\title{
Insights into the Teaching of Gradient from an Exploratory Study of Mathematics Textbooks from Germany, Singapore, and South Korea
}

\author{
Ban Heng Choy ${ }^{1^{*}}$, Mi Yeon Lee ${ }^{2}$, Angel Mizzi ${ }^{3}$ \\ ${ }^{7}$ National Institute of Education, Nanyang Technological University, SINGAPORE \\ ${ }^{2}$ Arizona State University, USA \\ ${ }^{3}$ University of Duisburg-Essen, GERMANY \\ *CORRESPONDENCE: $\gg$ banheng.choy@nie.edu.sg
}

\begin{abstract}
Textbooks, which form the staples of a teacher's set of resources, play a critical role in deciding what and how mathematics is taught in classrooms. However, textbooks do not always present concepts in ways that enhance understanding by students, nor are they always comprehensive in the treatment of a topic. In this exploratory study, we analyse three mathematics textbooks from Germany, Singapore, and South Korea to examine how gradient, an important but not wellunderstood concept, is presented. For each of the textbooks, we characterise the introductory chapter on gradient in terms of contextual (educational factors), content, and instructional variables in relation to the curriculum emphases across the three countries. In addition, we represent these findings using visual representations, which we called textbook signatures. We share insights from our analyses, raise questions, and suggest implications for future research in textbook analyses and ways to represent the findings from such analyses.
\end{abstract}

Keywords: textbook analyses, gradient, representations, task demands

\section{INTRODUCTION}

As a fundamental concept, gradient is relevant to both school mathematics and non-classroom contexts of everyday life. However, research suggest that students have difficulties in understanding the concept of gradient because of its multiple definitions and modes of representation (Stump, 2001; Walter \& Gerson, 2007). In her study, Stump (2001) found that high school pre-calculus students had limited conceptions of gradient, and struggled to make connections between various representations of concepts, particularly between rate of change and gradient. Other studies, such as those of Janvier (1981) and Orton (1983), also highlight similar difficulties faced by students in establishing the connection between graphs and the notion of rate of change.

What could have contributed to these difficulties when learning gradient? Walter and Gerson (2007) highlight that an over-emphasis on seeing gradient as 'rise over run' may have contributed to the students' difficulties in making connections among slope, line position, and rate of change. Similarly, Teuscher, Reys, Evitts, and Heinz (2010) reported that students showed "an incomplete understanding of the concepts of slope, rate of change, and steepness and of the relationships among them" (p. 522). Textbooks may also play a crucial role in introducing these ideas and highlighting the connections. For example, Teuscher et al. (2010) suggest that the different terms used in textbooks might be confusing to students, encountering gradient for the first

Article History: Received 16 March $2020 \bullet$ Revised 27 April $2020 \bullet$ Accepted 8 May 2020

(C) 2020 by the authors; licensee Modestum Ltd., UK. Open Access terms of the Creative Commons Attribution 4.0 International License (http://creativecommons.org/licenses/by/4.0/) apply. The license permits unrestricted use, distribution, and reproduction in any medium, on the condition that users give exact credit to the original author(s) and the source, provide a link to the Creative Commons license, and indicate if they made any changes. 
time. They fail to understand that these terms can be used interchangeably, and instead, perceive them rather as three unrelated concepts (Teuscher et al., 2010).

Here, we concur with other researchers (Charalambous, Delaney, Hsu, \& Mesa, 2010; Mayer, Sims, \& Tajika, 1995; Stigler, Fuson, Ham, \& Kim, 1986) that textbooks play an important role in shaping what and how mathematics is taught in schools for several reasons. First, textbooks are written to present mathematical ideas and teaching approaches intended by curriculum documents (Huntley, 2008; Usiskin, 2013). Second, teachers generally use textbooks for planning their lessons. And third, students use them when learning new mathematical ideas, or to deepen their understanding of notions and concepts. Textbooks are thus used as key resources for the teaching and learning of mathematics (O'Keeffe \& O'Donoghue, 2015), and they often form the "centerpiece of a course" (Usiskin, 2013, p. 715). In addition, the learning opportunities afforded by textbook tasks and explanations may provide insights into what and how gradient concepts are introduced and presented in mathematics textbooks. Therefore, textbooks serve as "a vehicle for learning mathematics" (Usiskin, 2013, p. 716) and are perceived to influence and impact mathematics learning (Wang, Barmby, \& Bolden, 2015).

Despite its importance, textbooks are often ignored in international comparative studies of educational systems (Altbach, 1987). Given that textbooks play an important role in presenting mathematical ideas, it is useful to analyse textbooks to identify areas for improvement in curriculum development. Moreover, results from international benchmark tests have put the spotlight on how different countries treat various topics in their curriculum. In particular, researchers are interested to see how countries which performed well in international benchmark assessments teach mathematics. Hence, examining how the same topic is taught across different countries may provide insights into how one can teach the topic differently. In this exploratory study, we investigate how three textbooks from Germany, Singapore, and South Korea present the topic of gradient. More specifically, our research is framed by the following research questions:

1. What conceptualizations of gradient are used, and in what order are they introduced?

2. What representations are used for the concept of gradient?

3. What levels of cognitive demands are required by the tasks in the textbooks?

4. What are the similarities and differences in how the textbooks present the concept and representations of gradient?

\section{TEXTBOOK ANALYSES: AFFORDANCES FOR COMPARING HOW CONCEPTS ARE TAUGHT}

Textbook analysis has attracted the attention of mathematics educators, but the development in research on textbooks is still under-theorized (Fan, Zhu, \& Miao, 2013). Theorizing textbook analysis is challenging because textbook analyses differ greatly in scope (Fan et al., 2013). For example, we can analyze a single textbook, or a series of textbooks within the same country, or across different countries. Adding to the complexity, textbook analysis can involve examining the development of a single topic through the same textbook series across school years, or across different textbooks in the same country. Moreover, one can focus on the development of the same topic across different countries to highlight the similarities and differences in how the topic is presented in textbooks. Despite the challenges involved in framing the scope of textbook analyses, textbook analyses are important because they enable mathematics educators to examine relationships between textbooks and their educational contexts to offer insights into the teaching and learning of mathematics in different countries (Son \& Diletti, 2017).

Many studies present findings from textbook analyses in terms variables such as mathematical concepts (Charalambous et al., 2010; Wang et al., 2015), or the type of problems presented in textbooks (Li, 2000; Stigler et al., 1986), or types of representations (Chang, Cromley, \& Tran, 2016). Often, these analyses are presented using tables, accompanied by excerpts from the textbooks, which allow comparisons for a particular variable. To compare textbooks with respect to more than one variable, one needs to create representations that highlight similarities and differences in multiple variables across different textbooks. For example, as part of the Third International Mathematics and Science Study (TIMSS) in 1995, Valverde, Bianchi, Wolfe, Schmidt, and Houang (2002) analyzed 630 Mathematics and Science textbooks from 40 countries to characterize the learning opportunities afforded by textbooks. They then presented their analyses of the physical features, the structures, and content presentation of textbooks in the form of schematic diagrams. 
Table 1. Proposed variables for our textbook analyses

\begin{tabular}{ll}
\hline Variables & Description \\
\hline Context variables & $\begin{array}{l}\text { Education system; academic year; time allocated for mathematics; number of textbooks; } \\
\text { publishing process; and curriculum emphasis. }\end{array}$ \\
\hline Content variables & $\begin{array}{l}\text { Conceptualizations of gradient (E.g., geometric ratio; algebraic ratio; physical property; } \\
\text { functional property; parametric coefficient; trigonometric conception; calculus conception; real- } \\
\text { world situation; determining property; behaviour indicator; and linear constant) } \\
\text { Definitions; rules; explanations; examples. }\end{array}$ \\
\hline Instructional variables & $\begin{array}{l}\text { Representations of gradient } \\
\text { Cognitive demand of tasks, exercises, and examples. }\end{array}$ \\
\hline
\end{tabular}

Taking a cue from Valverde et al. (2002), we build on Huntley's (2008) proposed content and instructional variables (2008), and integrate a horizontal and vertical analysis of the mathematical content (Charalambous et al., 2010) by representing our analyses visually. Three categories of variables (see Table 1) are included in our analyses of the selected textbooks from the three countries.

In this article, we first focus on context, content, and instructional variables as we analysed three selected textbooks to understand what and how concepts of gradient were presented. Next, to compare the similarities and differences of the three textbooks, we create our own visual representation in each of the textbooks for each of the three variables, which we referred to as "textbook signature." For the first variable, textbook signature demonstrates the distinct conceptualisations of gradient presented on each page (refer to Figure 2). For the other two variables, textbook signature shows the configurations for the frequencies of occurrence in each textbook by its histogram in which the numbers on the left side indicate the frequency and the numbers at the bottom show the sequence of textbook pages (refer to Figures 3 and 4). We believe that comparing the textbook signatures for each variable across the three selected textbooks is helpful for us to find any patterns resulting from our analyses, both visually and numerically. Last but not least, we suggest possible implications and directions for future work on textbook analysis.

\section{CONTEXT VARIABLES}

Echoing the belief espoused by Valverde et al. (2002), we see textbooks as critical mediators between a country's curricular intentions and specifications, and the classroom implementation of the curriculum. By examining the extent to which textbooks reflect the intended curriculum, and how they communicate the intended curriculum, we can gain important insights into the teaching and learning of mathematics in different countries (Wang et al., 2015; Valverde et al., 2002). Hence, in this section, we describe the educational contexts of the three countries so that the findings can be compared and contrasted in relation to the contexts.

\section{Educational Contexts of Germany}

Germany has a decentralized education system in which school curricula are determined by each state. Secondary education is compulsory and usually covers grades 5 to 12 , in what they designate as grammar schools. Since there are different types of secondary schools, this textbook analysis will focus on students who pursue their general qualification to enter university studies. In Germany many textbook series available from private publishing companies. These books must be approved by the Ministry of Education of each German state in order to ensure that they satisfy the national standards provided by the Conference of Federal Culture Ministers (KMK - Konferenz der Kultusminister der Länder). The German mathematics curriculum focuses mainly on modelling, problem solving, argumentation and reasoning, and communication (Beschlüsse der Kultusministerkonferenz, 2004).

\section{Educational Contexts of Singapore}

Singapore has a centralised education system, which has evolved over the past five decades since the country's independence in 1965. Education is compulsory for the primary levels (aged 7 - 12) and about 98\% of each cohort of students qualify for the secondary schools after the Primary School Leaving Examination, a milestone placement assessment at the end of the primary school (Ministry of Education-Singapore, 2018). There are three main courses for the secondary schools: Express, Normal Academic (NA) and Normal Technical (NT). The Express Course is a four-year course leading to the Singapore-Cambridge General Certificate of Education (GCE) O-Level exam. For more details on the other two courses, interested readers may refer to Ministry of Education-Singapore (2018). For this article, we will focus on the Express Course, which is taken by more than $60 \%$ of the students in each cohort (Ministry of Education-Singapore, 2018). 


\begin{tabular}{|c|c|c|c|c|}
\hline & & GERMANY & SINGAPORE & SOUTH KOREA \\
\hline \multirow{6}{*}{ 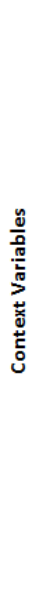 } & Educational System & Decentralized & Centralized & Centralized \\
\hline & Secondary Education & $\begin{array}{l}\text { Mainly three types of secondary schools with } \\
\text { different academic standards: Gymnasium } \\
\text { (preparation for university), Realschule (for } \\
\text { apprenticeships) and Hauptschule (for } \\
\text { vocational qualifications) }\end{array}$ & $\begin{array}{c}\text { Different secondary courses: Express/Special, } \\
\text { Normal Academic, Normal Technical }\end{array}$ & $\begin{array}{l}\text { Two types: Academic school to } \\
\text { advance to University and Practical } \\
\text { school to get a job }\end{array}$ \\
\hline & Academic Year (in weeks) & $39-40$ & 40 & 40 \\
\hline & Allocated time for Mathematics & Varies. About 4 to 8 hours per week & 4 to 5 hours per week & Varies. About 4-5 hours per week \\
\hline & Curriculum Emphases & $\begin{array}{l}\text { Application to real-life situations and } \\
\text { modelling, problem solving, and reasoning. }\end{array}$ & $\begin{array}{l}\text { Problem solving with five strands of } \\
\text { emphases: Conceptual understanding, skill } \\
\text { proficiency, mathematical processes, } \\
\text { attitudes and metacognition. }\end{array}$ & $\begin{array}{l}\text { Understanding fundamental } \\
\text { mathematical concepts; developing } \\
\text { mathematical thinking and } \\
\text { communication skills in creative } \\
\text { ways; improving attitudes towards } \\
\text { mathematics. }\end{array}$ \\
\hline & $\begin{array}{l}\text { No. of textbook and publishing } \\
\text { context }\end{array}$ & $\begin{array}{l}\text { Multiple, published by private publishing } \\
\text { companies and need to be approved by the } \\
\text { Ministry of Education. }\end{array}$ & $\begin{array}{c}\text { Two textbooks available, both written by } \\
\text { private publishing companies and approved by } \\
\text { the Ministry of Education. }\end{array}$ & $\begin{array}{l}\text { Mutiple, all textbooks are published } \\
\text { by private publishing companies and } \\
\text { need to be approved by the Ministry } \\
\text { of Education. }\end{array}$ \\
\hline
\end{tabular}

Figure 1. An overview of the contexts of the three countries.

The Singapore Mathematics curriculum is guided by the central focus on problem solving, with five other emphases-Concepts, Skills, Processes, Attitudes, and Metacognition (Kaur, 2019)—since the early 1990s. The most recent refinement to the curriculum focuses on developing mathematics processes in our students (Ministry of Education-Singapore, 2012), and positions the meaningful mathematics tasks, or learning experiences, as a key initiative (Kaur, 2019).

\section{Educational Contexts of South Korea}

South Korea also has a centralized education system. Compulsory secondary education usually corresponds to grades 7 to 9 . Multiple mathematics textbooks are available from private publishers, but all texts are subject to the Ministry of Education's approval before publishing. Each secondary school selects one of the approved textbooks. The South Korean mathematics curriculum emphasizes conceptual understanding and aims to develop mathematical attitudes, thinking and communication skills in a creative way. The textbook used for this study was published by the Kum Sung Publishing Company and based on the 9th revised Korean mathematics curriculum, was part of a popular textbooks series in South Korea. In summary, we represent the contexts of Germany, Singapore, and South Korea in Figure 1.

\section{CONTENT VARIABLES: CONCEPTUALIZATIONS OF GRADIENT}

Gradient of a line is often conceptualized as a measure of its steepness. Informally, teachers often introduce the notion of gradient using real-world situations such as the slopes of a mountain (Zaslavsky, 2010). However, as highlighted by Stump (1999), textbooks usually define "the slope of a line as the ratio of the vertical rise to the horizontal run as you move from one point to another along the line" (p. 125). This geometric perspective of gradient is usually amongst the first conceptualization of gradient introduced together with a more physical interpretation of gradient as the physical steepness of a line. At a more advanced level, slope can be associated with the parameter $m$ in the $y=m x+b$ form of the linear function. This parametric view of gradient is different from a geometric perspective of gradient of a line because the parametric conceptualization implies that gradient is an invariant property of a line regardless of the scale in which the graph of the function is drawn (Zaslavsky, Sela, \& Leron, 2002). Besides these conceptualizations of gradients, one can interpret gradients in terms of the angle between the graph and the axes (Zaslavsky et al., 2002), and as a rate of change between variables, and as a limit in the case of tangent lines to a point on the curve (Stump, 2001). Therefore, there are many ways to perceive gradient. Moore-Russo, Conner, and Rugg (2011) suggest that there are 11 conceptualisations of gradient, which were adopted as content variables in this study. These gradient concepts are:

1. Geometric ratio, as the ratio $\frac{\text { Rise }}{\text { Run }}$ or vertical displacement over horizontal displacement;

2. Algebraic ratio, as the ratio $\frac{y_{2}-y_{1}}{x_{2}-x_{1}}$ or change in $y$ over change in $x$;

3. Physical property, such as "steepness" as a property of a line; 
4. Functional property, as the (constant) rate of change between variables in multiple representations;

5. Parametric coefficient, as a parametrical coefficient $m$ in the equation $y=m x+b$;

6. Trigonometric conception, as the tangent of a line's angle of inclination;

7. Calculus conception, in reference to the tangent line to a point in a curve;

8. Real-world situation, as in a physical object (e.g. a ramp) or a dynamic, functional situation;

9. Determining property, as a property which characterizes parallel or perpendicular lines;

10. Behaviour indicator, as a property which characterizes the increasing, decreasing, or constant trend of a line and the increase or decrease of a line; and

11. Linear constant, as a property which is unaffected when a line is translated.

\section{INSTRUCTIONAL VARIABLES}

Many teachers use textbooks as a major resource in their teaching. In this paper, we will consider two key instructional variables-modes of representations of gradient and cognitive demand of tasks-in our examination of the textbooks. As highlighted by Smith and Stein (1998), the cognitive demand of tasks is influenced by the use of representations in the tasks and the opportunities given to students to make connections between these different representations. While acknowledging this connection, we also wanted to focus on how textbook writers explain the concept of gradient using representations through the worked examples and explanations in the textbook. Together with our analysis of the tasks' cognitive demand, the analysis of how different modes of representations are used in the explanations and examples will provide a more comprehensive view of the concept of gradient is presented in these textbooks.

Different modes of representation are used to present mathematical knowledge in textbooks. We distinguish between four major types of representations of the introductory notion of gradient in our textbook analysis. The first representation is pictorial, which refers to the use of pictures of real-life situations to concretely illustrate the notion of gradient (e.g. a picture of a ramp). The second is numerical representation, which involves the use of tables and the relationships among values in tables to quantitatively denote its properties. The third, symbolic representation, translates conceptualizations into the mathematical language of variables and equations, and the last, graphical representations, provides a visual construction of the notion of gradient by using graphs.

Another important criterion used for analyzing textbooks is the cognitive demand inherent in the textbook tasks. Smith and Stein (1998) have classified tasks according to lower and higher level demands by analysing "the potential of tasks to support student's thinking and reasoning" (p. 16). On one hand, the lower cognitive demands of tasks include memorization and mastery of procedures without making connections. In memorization tasks, students reproduce previously learned knowledge (such as formulas, rules, etc.) to solve a task. Applying procedures without connections involves the use of algorithms, which are usually evident in the task instructions. Additionally, these tasks focus primarily on providing the correct answer rather than developing mathematical understanding. On the other hand, higher-level demands consist of two types of tasks, applying procedures with making connections and doing mathematics. In the former, students use procedures to develop a deeper understanding of underlying mathematical concepts and use different types of representation modes to carry out tasks. Such tasks are considered as a high cognitive demand because students need to understand salient mathematical concepts underlying the procedures to complete tasks successfully. Tasks that involve doing mathematics are characterised by the use of complex and nonalgorithmic thinking. These tasks require students to self-regulate their cognitive processes and access deep understanding of relevant mathematical concepts to develop solutions themselves.

\section{METHODS}

\section{Textbook Selection}

All textbooks from the three countries are written by private publishers and are subjected to approval by the local authority before publishing. At the time of this study, only two secondary mathematics textbook series were available for the Express Course in Singapore whereas multiple mathematics textbooks in South Korea and Germany. Three secondary mathematics textbooks, Elemente der Mathematik 8 from Germany, Discovering Mathematics-2nd Edition from Singapore, and the 8th grade Kum Sung math textbook from 
South Korea, were chosen for this study. The German textbook Elemente der Mathematik 8, published by Schroedel Publishing Company, represented the traditional German grammar school curriculum at Grade 8 of the upper-secondary school form Gymnasium. The secondary school form of Gymnasium was chosen for the German case because it represents the typical school form for students pursuing their A-Levels as a schoolleaving certificate. Furthermore, the mathematics textbook was approved for use in schools in the majority of German federal states according to KMK (Kulturminister Konferenz) and exerted a strong influence on more recently published textbooks. The textbook from Singapore was one of the two approved textbooks for the 2013 syllabus for Mathematics (Express) and was widely adopted by many schools. Similarly, the textbook published by the Kum Sung Publishing Company and based on the 9th revised Korean mathematics curriculum, was part of a popular textbook series in South Korea.

\section{Data Analysis}

We view textbooks as "objectively given structure", which emphasize their content presentation and structure without referring to how they may be used by teachers and students in classrooms (HerbelEisenmann, 2007, p. 346). We reviewed curriculum documents and the textbook chapters that covered the gradient concepts. Then, each researcher coded the selected chapters for three variables: conceptualizations of gradient, representations of gradient (e.g., pictorial, numerical, graphical, and symbolic); and cognitive demands of tasks, exercises and examples. To ensure the reliability of the coding for these three variables, we first coded the Singaporean textbook independently because it was written in English, and then checked for discrepancies in our interpretations of the codes. After reconciling our discrepancies, we systematized our coding notes as a reference. We now detail how we reconciled these discrepancies.

\section{Reconciling differences in coding gradient conceptualizations}

For instance, we initially differed in our perspectives used for coding gradient conceptualizations: the students' perspective or the textbook authors' intention. We decided to code tasks based on clear descriptors given in the text without assuming either the students' or the textbook authors' perspectives. For example, referring to Task 1 from Discovering Mathematics-2nd Edition, p. 95:

\section{Task 1}

(a) Copy and complete the table for the line $y=-2 x+3$.

\begin{tabular}{|c|c|c|c|c|c|}
\hline$x$ & -2 & -1 & 0 & 1 & 2 \\
\hline$y$ & 7 & 5 & 3 & 1 & -1 \\
\hline
\end{tabular}

(b) Using a scale of $1 \mathrm{~cm}$ to 1 unit on both axes, draw the graph of $y=-2 x+3$ for $-2 \leq x \leq 2$.

(c) Hence, find the gradient of the line.

We see that Task 1 can involve three conceptions depending on how students find gradient: functional property (when finding the constant rate of change in (a)); geometric ratio (when drawing a graph and finding vertical and horizontal distances between two points in (b)); and parametric coefficient (when using the coefficient of $y=-2 x+3$ as a gradient in (a) or (b)). In this case, we coded the tasks as geometric ratio from the clear instructions to draw the graph in (b).

\section{Reconciling differences in coding representations}

In addition, we clarified how we defined each representation along with examples from the Singaporean textbook by creating coding notes. Pictorial representation was defined as pictures directly related to the concept of gradient (e.g., stair or ramp pictures). Symbolic representation was defined as any formula that was directly related to the concept of gradient (e.g. Change in y over change in $\mathrm{x}$, or the coefficient, $\mathrm{m}$, in a linear function $\mathrm{y}=\mathrm{mx}+\mathrm{b}$ ) or any process for putting numbers into a formula in order to show how to calculate a gradient. So, we did not count general algebraic expressions without relationship to the concept of gradient as symbolic representations. Numerical representation was limited to tabular representation and graphical representation was defined as linear graphs whether or not on graph paper.

\section{Reconciling differences in coding tasks}

When classifying tasks, we faced three major discrepancies. Although we could easily distinguished between the low cognitive demand tasks of memorization and applying procedures without connections, it was 
challenging to distinguish between a procedure with connection task and a doing mathematics task. For example, consider the following Task 2 taken from Discovering Mathematics-2nd Edition, p. 96:

\section{Task 2}

(a) Name three public buildings that have access ramps at the entrance for people with wheelchairs.

(b) Search online for the maximum gradient for a local access ramp for wheelchairs.

(c) Based on your result in (b), find the minimum horizontal length of a ramp required for a vertical rise of $0.5 \mathrm{~m}$.

Initially, two out of three researchers coded the problem as a doing mathematics task because of its open nature and its relation to real-life experiences. However, the third researcher coded it as a procedure with connection task in that (1) the sub-questions (a) and (b) do not relate to math in that they just ask students to identify accessible buildings and find information about the use of ramps; and (2) if students know this information, the sub-question (c) provides a clear pathway to the answer. Through discussion, we reconciled this discrepancy by coding the problem as a procedure with connection task because we agreed that if the last question asks students to find some relationship between a particular building's ramp and the maximum or minimum of horizontal distance, it could be coded as doing mathematics but not the current problem as it is.

The second issue arose when similar tasks using different contexts were consecutively presented in the textbook. When focused on the task itself, both questions could be coded as procedure with connection tasks. However, if teachers demonstrate the solution to the first problem in a series of problems and ask students to solve the next one, the cognitive demand of the task will be lowered because students could simply apply the procedures as demonstrated. Hence, we decided to focus on the problem itself because, given the frequency of this design in textbooks, we might end up coding most questions as procedure without connection tasks.

The third issue arose when a task included several sub-questions. There were instances in which the first sub-question is coded as procedure without connection and the other two sub-questions are procedure with connection tasks. Here, we decided to code the overall tendency of each task rather than coding each subquestion separately because textbooks usually provide tasks from easy to difficult levels to allow multiple entry points for students. Thus, we coded such tasks according to the sub-question with the highest cognitive demand.

Through these negotiations, we agreed on the coding of the tasks provided in the textbook. After reliability was established, we analysed the three textbooks using the codes of the three variables. Lastly, we created the textbook signature for each selected textbook by representing how these three variables co-occurred on each page (see Figures 2-4). The patterns were then interpreted within the textbook as well as in light of the wider educational context of the country.

\section{RESULTS AND FINDINGS}

In this section, we present the findings of our analyses using our notion of textbook signature before discussing how gradient was presented in the different textbooks, in relation to the contextual factors in each country.

\section{Conceptualizations of Gradient}

\section{German textbook: Myriad of conceptualizations}

One of the most visible results in the comparison of the gradient conceptualisations is that the German textbook focuses on several conceptualizations of gradient simultaneously across the 11 pages in the chapter introducing gradient.

Referring to Figure 2, we see that gradient in the German textbook is first introduced as a geometric ratio, physical property, behaviour indicator, algebraic ratio, real-world situation, and parametric coefficient. These different conceptualizations of gradient are introduced by referring to the differing steepness of two streets and mathematizing it using the gradient triangle and proportional functions. After the steepness of a street is introduced as a percentage (e.g., $20 \%$ steepness), it is translated into a quotient, thus the geometric ratio. This is followed by the modelling of a street in a coordinate system using a line, and representing the geometric ratio with a gradient triangle. Using the geometric ratio, the gradient of the line is introduced as a parameter in a proportional function. In the next example, the German textbook introduces the notion of negative gradient by giving an example of a downward slope of a street, which is modelled as a linear function in a 


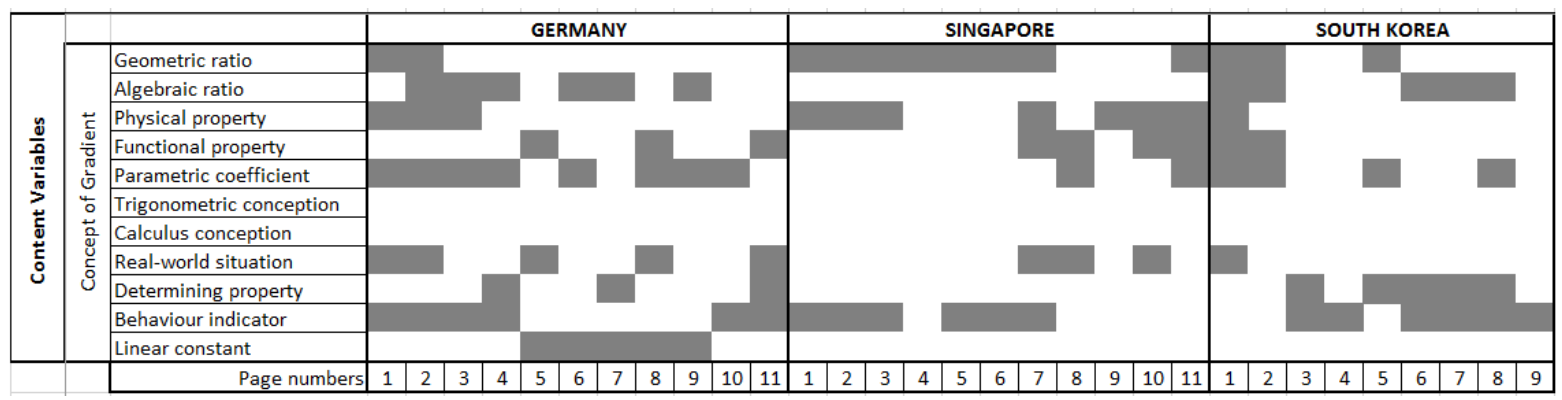

Figure 2. Conceptualisations of gradients across the three countries

coordinate system. In the next pages of the book, the notion of linear function is introduced, together with other conceptualizations of gradient, such as functional property, determining property and linear constant. For example, the conceptualization of linear constant is introduced with an example of a linear function, which describes the weight ( $x$ - Volume of gravel, $y$ - Weight), consisting of the gravel weight, $2 x$ tons and trailer weight of 3 tons. The first example considers the gravel weight $y=2 x$ and visualizes the unaffected property of gradient while adding the trailer weight to the gravel weight.

\section{Singapore textbook: Primarily geometric}

In Singapore, gradient is introduced primarily as a geometric ratio, with references to the steepness of a line (physical and behavioural) without using the algebraic ratio notion. As seen in Figure 2, these conceptualizations give way to others such as functional and parametric coefficients when connections are made to the notion of the equation of a straight line. In addition, gradient is related to real-world situations in some of the tasks. The concept of gradient in Singapore is first introduced as a key feature of the graph of a linear function, and defined as the ratio of the vertical change to the horizontal change (see Figure 2). This is interesting because the concept of linear functions is presented before gradient. It is important to note that students are not expected to know what the parameters of $a$ and $b$ are even though the form of the equation of a linear function $(y=a x+b)$ is taught before the concept of gradient is formally introduced as a geometric ratio.

The exposition of gradient starts with introducing positive gradients, followed by negative gradients, and then concludes with special cases involving horizontal and vertical lines. The geometric ratio notion of the gradient of a line is associated with a numerical measure that gives "some sense of its steepness." Other notions of gradients are introduced briefly after the concept of gradient as a geometric ratio is developed. For example, a gradient as a rate of change is introduced at the end of the chapter through a Class Activity. Here, the students are expected to understand the gradient, a, of a straight line, $y=a x+b$, as the rate of change of $y$ with respect to $x$. They are also expected to interpret the physical significance of gradients of straight-line graphs in real-life situations. For example, in Task 3, we have:

Task 3

$$
\begin{aligned}
& \text { The production cost, } \$ y \text {, of printing } x \text { copies of a book is given by the function: } \\
& y=5 x+2000 \text {; Interpret the physical meaning of the gradient } 5 \text { in the function. (p. 94). }
\end{aligned}
$$

However, students are not expected to extend this notion to finding gradients of curves, although they will learn how to determine the gradients of a point along a curve using graphical methods in Secondary Two (ages 13-14). The notions of negative gradients and gradients of horizontal lines and vertical lines are consistently developed from the geometric ratio conception. For example, the concept of a negative gradient is associated with a negative vertical change, but the geometric steepness is given by the magnitude. Likewise, the gradient of horizontal lines is explained to be zero because the vertical change is zero. Similarly, the gradient of vertical lines is said to be undefined because the horizontal change is zero.

A real-world situation, illustrating gradient, is also introduced through an analogy of the increase in the amount of effort taken to climb up a slope in relation to increases in the steepness the gradient. This analogy is used to introduce gradient and explain zero gradient and undefined gradient. It is arguable whether one expends effort to walk a horizontal distance, depending on one's definition of effort. Using the same analogy, a vertical line is said to be "very steep" and that it "needs a lot of effort" to climb. This analogy, however, is not extended to the explanation of negative gradients. 


\section{Korea textbook: Connecting geometric to algebraic}

In South Korea, the concept of gradient is introduced in relation to the steepness of a staircase before this familiar situation is compared with determining gradients in graphical representations using a geometric ratio. Based on this initial introduction, the concept of gradient is formally defined as an algebraic ratio with basic comments on the notions of functional property and parametric coefficient. Later, the main focus changes from the notion of gradient to its determining property and behaviour indicator in connection with a linear function. Below we present in more detail along with examples from the textbook.

The Korean textbook introduced gradient using the example of the steepness of a staircase to define gradient as $\frac{\text { Vertical Distance }}{\text { Horizontal Distance }}$. Then, the procedure for finding a gradient in a linear function is explained by referring to a real-life situation. With the aid of a graph, the concept of gradient is introduced as a key feature of the graph and defined as the ratio of the vertical change to the horizontal change along with short and explicit comment on constant rate of change. Based on the concept of geometric ratio, the concept of gradient is formally defined as "change in $y$ over change in $x$," and the coefficient $m$ in the linear function, $y=m x+b$. Also, the notion of gradient of a line is associated with the property that determines parallel lines, and then the property that indicates increasing or decreasing trends of line. However, special cases involving horizontal and vertical lines are not covered here.

In sum, comparing three countries' textbooks, we see that the different emphases in the conceptualizations reflect the curriculum focus in each country to a large extent. First, none of the textbooks featured trigonometric and calculus conceptions because these are more advanced notions that are not required when gradient is first introduced. Secondly, the wider range of conceptualizations of gradient in the German textbook seems to reflect the curricular emphasis on modelling, which demands different notions to be represented simultaneously. In contrast, there seems to be a more structured and distinct transition in the conceptualisations in both the Singaporean and South Korean textbook, which may reflect the curriculum focus on gradient as part of a larger unit on linear functions.

\section{Representations of Gradient}

The typical pictorial representation of gradient in the German textbook includes photographs, which activate practical knowledge relevant to the underlying concept of gradient in situations such as the slope of a road. In contrast, no pictorial representation of gradient is used in the Singaporean textbook, and numerical representations are only introduced in conjunction with graphical and symbolic ones, when linear graphs are used in the context of a task.

The South Korean textbook includes 45 instances of four types of representations. The symbolic representations are the most frequent (23 instances) and followed by graphical representations (18 instances). Graphical and symbolic representations appear together because of the emphasis on translations between graphical and symbolic representations. There are two instances each of pictorial representations and numerical representations. The pictorial representations are used when the topic is introduced in order to motivate students at the beginning. Numerical representations are used only to indicate the algebraic ratio, rather than to encourage students to find the patterns of constant rate of change for the functional property of gradient.

Comparing three countries' textbooks as seen in Figure 3, there are two noteworthy aspects with regard to the use of representations: the density and its association with the conceptualizations. First, the German textbook seems to have "denser" representation patterns per page, as compared to the other two textbooks. This difference may be associated with the type of tasks and conceptualisations emphasized in the textbooks. For example, in the German textbook, there seems to be a deliberate relationship between the real-world experience of gradient and the use of pictorial representations. This may be due to the use of pictures to help students make sense of the problems that are set in a real-life context.

On the other hand, the Singaporean and South Korean textbooks have similar representation patterns that are less dense and more focused on graphical and symbolic representations. This pattern reflects their focus on the gradient of straight lines rather than modelling real-life situations as the main context. Nevertheless, while the South Korean textbook seems to emphasize algebraic representations reflecting a focus on algebraic conceptualization, the Singaporean textbook has fewer symbolic representations because gradients are determined mostly through the geometric ratio without reference to algebraic conceptualization. 


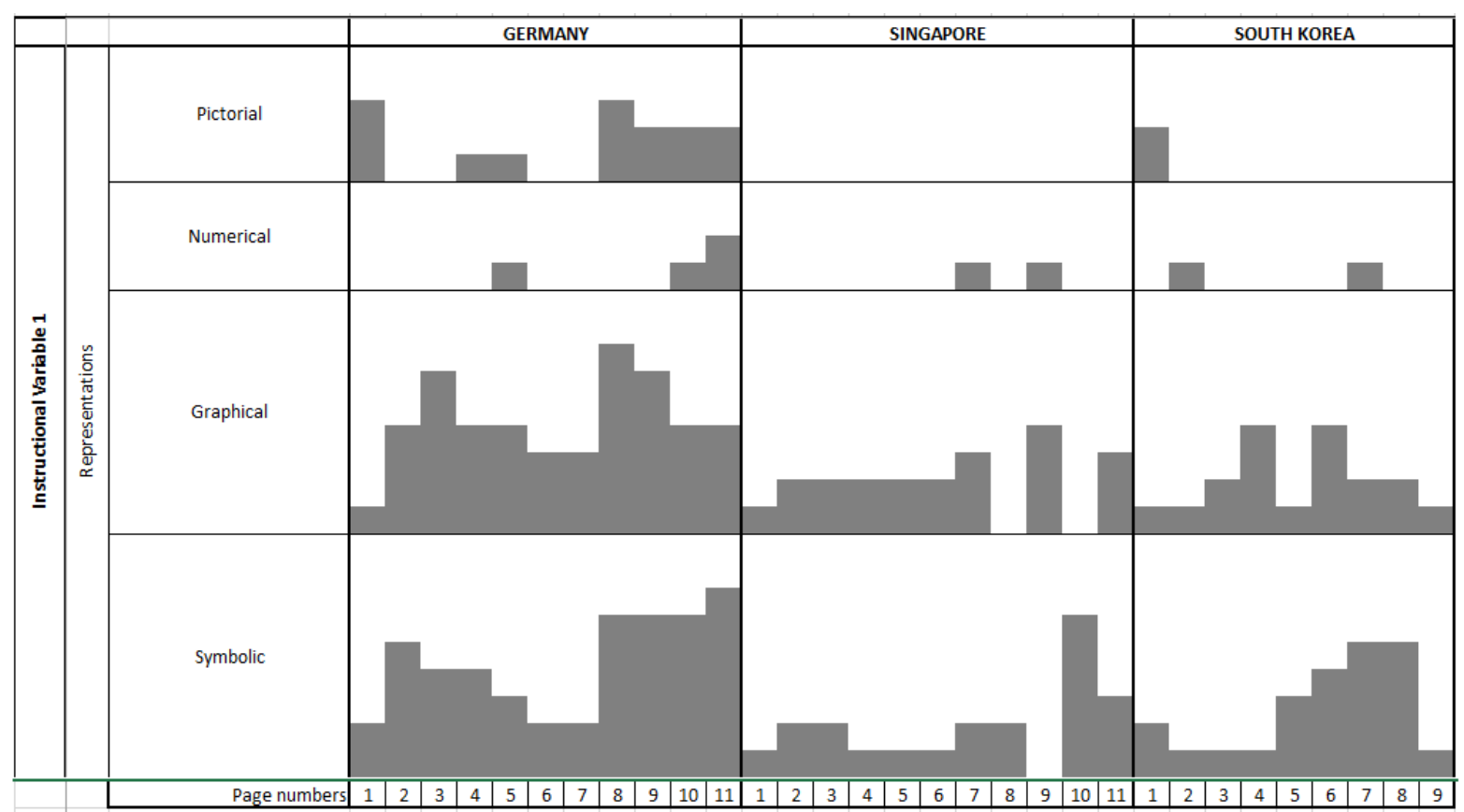

Figure 3. Representations of gradients in the three countries

\section{Cognitive Demand of Tasks}

In the German textbook, whereas all four types of cognitive demand problems are present, most can be classified as procedure without connection (70\%). In an example of this type of task, the student is directed to draw the graph of proportional function through the origin and the given units of the gradient triangle, and then find the gradient and the equation of the function. Solving process such a task does not necessarily require a deep connection to the concept of gradient, but rather the application of previously learned procedures. Moreover, the algorithm required to find out the gradient of the line is evident in the task instructions (e.g. 1 unit to the right, and 1,6 to the top), thus classifying the task as procedures without connections. The next most frequent tasks in the German textbook are procedures with connections, which constitute $19 \%$ of the total. Tasks of doing mathematics (6\%) and memorization (5\%) are present to a much lesser extent.

Similarly, in Singapore, majority of the examples are computational in nature, and hence they are classified as procedures without connections (56\%). The higher-demand questions (36\%) are found at the end of the section, and the layout of the questions seems to follow a sequence from less to more cognitively demanding. An interesting observation is that the formula for calculating gradients using coordinates is not introduced in the textbook. Instead, students are expected to apply the definition of gradient directly to compute the slope of a line in a Cartesian coordinate system. The questions under Examples are computational and hence can be characterised as lower-level demands.

The exercises are classified into three levels: Level 1 and 2 questions consist mainly of the lower-level demand types, and Level 3 consists mainly of higher-level demand questions that require students to apply procedures with connections. There are two tasks on gradient in the Class Activity for this section, both classified as higher-demand (8\%). One is a task that requires students to investigate the effect of changing the parameters of a linear function. However, majority of the tasks are classified as 'procedures without connections' (52\%), followed by 'procedures with connections' (32\%). There are also two tasks classified as 'memorization tasks' (8\%). This distribution reflects the curriculum's emphasis in developing both procedural and conceptual fluency.

In contrast, tasks and examples in the South Korean textbook are classified largely as procedures with connections (50\%), while another $10 \%$ are classified as doing mathematics, totaling $60 \%$ with high-level cognitive demands. Procedures without connections tasks account for only $36 \%$ of the total, and memorization only $4 \%$. This emphasis on higher cognitive tasks shows a very different picture from that of either of the other countries' textbooks. 


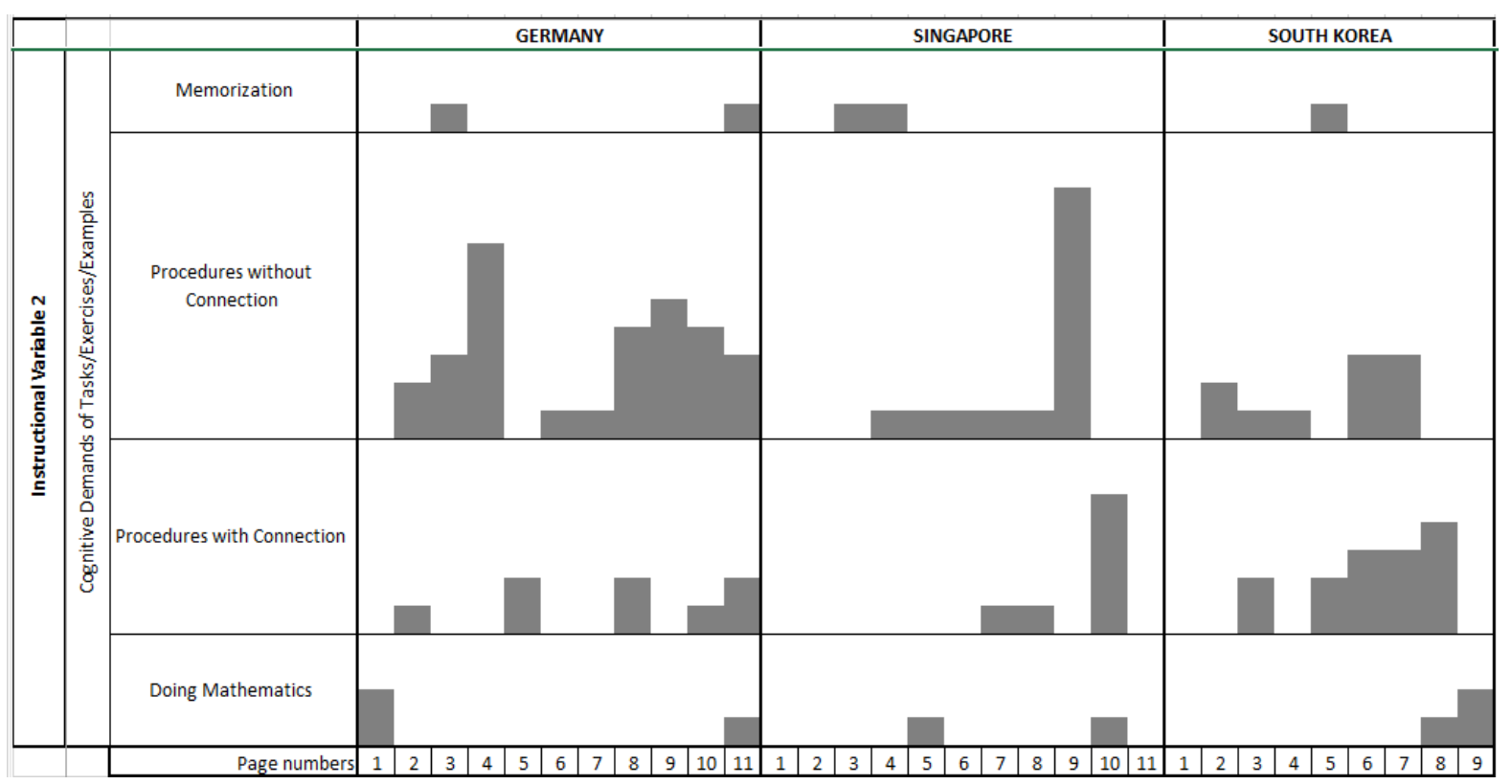

Figure 4. Cognitive demand of tasks in the three textbooks

Comparing the cognitive demand of tasks as seen in Figure 4, while all three textbooks appear to focus less on "memorization" tasks, at the same time, they include only a few "doing mathematics" tasks. In the German textbooks in particular, given their high representation density, varied conceptualizations of gradient, and examples that require complex mathematical thinking, it seems surprising that a sizable majority of the tasks for students involve procedures without connections and are not highly demanding (e.g., drawing a graph for a given equation or determining an equation for a given graph). In contrast, the cognitive demands of the tasks in the Singaporean textbook seem to reflect its curriculum approach of moving from simpler to more difficult problems. Likewise, the high use of tasks involving procedures with connections in the South Korean textbook is aligned with its curriculum emphasis on understanding mathematical concepts and its key focus on graphical-symbolic translations.

\section{DISCUSSION}

In this comparison of how the concept of gradient is introduced in German, Singaporean, and South Korean mathematics textbooks, both similarities and differences were observed in how they conceptualize and represent gradient. Both the German and the Korean textbooks define gradient in terms of algebraic ratio, but they differ in that the German textbook defines it with algebraic expressions and the South Korean textbook without algebraic expression. On the other hand, the Singaporean textbook defines gradient in terms of geometric ratio. Regarding representations, the German textbook, which reflects a curricular emphasis on real-life situations and uses various conceptualizations of gradient, features pictorial representations more often than the other two textbooks and overall a greater density of representations. The Singaporean textbook uses more graphical representations than the Korean textbook because it approaches the concept of gradient mainly in terms of geometric ratio. The South Korean textbook uses more symbolic representations as it heavily depends on the conceptualization of algebraic ratio to introduce the concept of gradient.

These findings suggest that the structure of textbooks and the way of introducing the concept of gradient are aligned with the curriculum emphasis of each country. This result corroborates previous research indicating that textbooks mediate between curriculum documents at national levels and actual activities implemented in classrooms (Valverde et al., 2002). This finding also suggests that there is a relationship between the conceptualizations of gradient and the representations used, showing that the textbooks of each country have their own unique features (Charalambous et al., 2010; Valverde et al., 2002).

This textbook analysis also reveals both strengths and weaknesses, and suggest ways to improve the design of textbooks. In terms of the strengths, the German textbook focuses on making connections between mathematical concepts and real-world situations while Singaporean and Korean textbooks are mathematically well structured. However, in order to more fully support the development of mathematical 
processes, textbooks in all three countries need to include multiple representations more evenly. In all three textbooks, graphical and symbolic representations are highly predominant over other representations. There is a need to provide more opportunities for students to find constant rate of change shown in tables or pairs of multiple coordinate numbers by including more numerical representations. To do so, textbook authors can weave in opportunities for students to make explicit connections between the numerical, graphical, and symbolic representations of gradients in the tasks presented in their textbooks. This improvement could help address the difficulty that students have shown in prior research such as making connections between rate of change and gradient (Stump, 2001), as well as provide more opportunities for them to think of gradient in terms of its functional property.

Also, the Singaporean and Korean textbooks should include more activities to connect conceptualizations of gradient with modelling, through which the conceptualizations covered in their textbooks might be extended to include the concept of linear constant or functional property. The Singaporean textbook, in which conceptualization of gradient heavily depends on the concept of geometric ratio, needs to feature a wider variety of conceptualizations, especially in light of prior research showing that the "rise-over-run" concept based on geometric ratio may cause students' difficulties in making connections among different conceptualization of gradient (Walter \& Gerson, 2007). Also, to develop students' problem-solving abilities and conceptual understanding, which are emphasized in both Singaporean and Korean curriculum documents, their textbooks need to focus on making connections among different conceptualizations of gradients as represented in pictorial, numerical, graphical, and symbolic forms. This recommendation is important because students can access the abstracted mathematical concept of gradient only through the representations, and the depth of their understanding relies on whether students make sense of relationships among different representations and internalize them (Webb, Boswinkel, \& Dekker, 2008).

\section{Limitations and Implications for Future Research}

Our construction of textbook signatures suggests a way to examine and represent the distinctive patterns in textbooks from different countries. As seen from our textbook signatures, the conceptualisations of gradient, gradient representations, and the cognitive demand of tasks, can be visually represented. This visualisation affords a quick comparison of how the concept of gradient is presented across three different countries. While our visualisation seems to offer some exciting possibilities, there are also several issues with it.

First, this exploratory study looked at a limited but purposive sample of textbooks from each of the three countries. In particular, the representations of German and South Korean textbooks can be improved by drawing a larger sample from the textbooks authorized in these countries. This raises the question of how analyses of a single topic from different textbooks within the same country can aggregated for an effective visualisation. Furthermore, in a de-centralized system, it is common for textbooks to be written according to different pedagogical traditions. As a result, "summing" or "averaging" the counts of the various variables may not make sense. How analyses of different textbooks can be combined in a visual form to paint a more representative portrait of textbooks in a country will be a fertile area for comparative research in textbooks. Doing so will help address the dearth of framework needed to make textbook analysis relevant and meaningful (Son \& Diletti, 2017).

Second, we constructed textbook signatures for the introduction of gradient. The concept of gradient may be revisited in another textbook targeted at a higher level of study. For example, the algebraic ratio conceptualization (Moore-Russo et al., 2011) is taught later at Grade 9 in Singapore. In this study, we did not examine the development of gradient across different years of study. Consequently, whatever we learn about the presentation of gradient concepts may be limited. To get a more complete picture of how textbooks in different countries present a particular concept, it is necessary to examine the concepts across different textbooks of the same series. Do we then combine different textbook signatures of gradient across different textbooks of different years by placing them side by side?

Third, only the concept of gradient was investigated in this exploratory study. However, there are other mathematical topics within the same textbook. Should other topics be analyzed and textbook signatures be developed for each topic? If so, how can a general textbook signature for each country be constructed representing different topics? Or would it better to construct textbook signatures for different topics and then get a sense of the distinctive patterns by looking through all the textbook signatures? Further investigation on formulating and representing these signatures and clarifying characteristics of textbook signatures within the same country, and among different countries, will be useful in the field of textbook analyses. 
Notwithstanding the limitations, our exploratory study to represent findings from textbook analyses in a visual way suggests some potential uses for representations such as our textbook signatures. Furthermore, our approach suggests that it is possible to apply a consistent frame to analyze textbooks from different countries and present them in ways that offer a quick overview of the distinctive patterns present in textbooks. For example, visual representations can reveal general alignment between textbook variables and curriculum emphases of a country. From our analyses, we hypothesize that there may be distinctive patterns in the textbook signatures which correspond to particular beliefs about how mathematics is learned and taught. Though our findings are still preliminary, our analyses reveal the underlying structures of the textbooks we examined. Last but not least, our textbook signatures provide a visual representation of the strengths and areas for improvement in the design of textbooks. As we have highlighted, more work is needed for our notion of textbook signatures to be robust enough for meaningful comparisons and analyses. As such, it remains to be seen whether our current notion of textbook signatures can be adopted, adapted, or revised to advance the field.

\section{Disclosure statement}

No potential conflict of interest was reported by the authors.

\section{Notes on contributors}

Ban Heng Choy - National Institute of Education, Nanyang Technological University, Singapore.

Mi Yeon Lee - Arizona State University, USA.

Angel Mizzi - University of Duisburg-Essen, Germany.

\section{REFERENCES}

Altbach, P. G. (1987). The Oldest Technology: textbooks in comparative context. Compare: A Journal of Comparative and International Education, 17(2), 93-106. https://doi.org/10.1080/0305792870170201

Beschlüsse der Kultusministerkonferenz. (2004). Bildungsstandards im Fach Mathematik für den Mittleren Schulabschluss Retrieved from https:/www.kmk.org/fileadmin/Dateien/veroeffentlichungen_ beschluesse/2003/2003_12_04-Bildungsstandards-Mathe-Mittleren-SA.pdf

Chang, B. L., Cromley, J. G., \& Tran, N. (2016). Coordinating multiple representations in a reform calculus textbook. International Journal of Science and Mathematics Education, 14(8), 1475 - 1497. https://doi.org/10.1007/s10763-015-9652-3

Charalambous, C. Y., Delaney, S., Hsu, H.-Y., \& Mesa, V. (2010). A Comparative analysis of the addition and subtraction of fractions in textbooks from three countries. Mathematical Thinking and Learning, 12(2), 117-151. https://doi.org/10.1080/10986060903460070

Fan, L., Zhu, Y., \& Miao, Z. (2013). Textbook research in mathematics education: Development status and directions. Zdm, 45(5), 633-646. https://doi.org/10.1007/s11858-013-0539-x

Herbel-Eisenmann, B. A. (2007). From intended curriculum to written curriculum: examining the "voice" of a mathematics textbook. Journal for Research in Mathematics Education, 38(4), 344-369. https://doi.org/10.2307/30034878

Huntley, M. A. (2008). A framework for analyzing differences across mathematics curricula. Journal of Mathematics Education Leadership, 10(2), 10-17.

Janvier, C. (1981). Use of situations in mathematics education. Educational Studies in Mathematics, 12(1), 113-122. https://doi.org/10.1007/BF00386049

Kaur, B. (2019). Overview of Singapore's educational system and milestones in the development of the system and school mathematics curriculum. In T. L. Toh, B. Kaur, \& E. G. Tay (Eds.), Mathematics Education in Singapore (pp. 13-34). Singapore: Springer. https://doi.org/10.1007/978-981-13-3573-0_2

Li, Y. (2000). A comparison of problems that follow selected content presentations in American and Chinese mathematics textbooks. Journal for Research in Mathematics Education, 31(2), 234-241. https://doi.org/10.2307/749754 
Mayer, R. E., Sims, V., \& Tajika, H. (1995). A comparison of how textbooks teach mathematical problem solving in Japan and the United States. American Educational Research Journal, 32(2), 443-460. https://doi.org/10.3102/00028312032002443

Ministry of Education-Singapore. (2012). O- and N(A)-level mathematics teaching and learning syllabus. Singapore: Curriculum Planning and Development Division.

Ministry of Education-Singapore. (2018). Education Statistics Digest. Singapore: MOE.

Moore-Russo, D., Conner, A., \& Rugg, K. I. (2011). Can slope be negative in 3-space? Studying concept image of slope through collective definition construction. Educational Studies in Mathematics, 76(1), 3-21. https://doi.org/10.1007/s10649-010-9277-y

O'Keeffe, L., \& O’Donoghue, J. (2015). A role for language analysis in mathematics textbook analysis. International Journal of Science and Mathematics Education, 13(3), 605-630. https://doi.org/10.1007/s10763-013-9463-3

Orton, A. (1983). Students' Understanding of Differentiation. Educational Studies in Mathematics, 14(3), 235250. https://doi.org/10.1007/BF00410540

Smith, M. S., \& Stein, M. K. (1998). Selecting and creating mathematical tasks: From research to Practice. Mathematics teaching in the middle school, 3(5), 344-350.

Son, J.-W., \& Diletti, J. (2017). What Can We Learn from Textbook Analysis? In J.-W. Son, T. Watanabe, \& J.-J. Lo (Eds.), What matters? Research trends in international comparative studies in mathematics education (pp. 3-32). Cham, Switzerland: Springer. https://doi.org/10.1007/978-3-319-51187-0_1

Stigler, J. W., Fuson, K. C., Ham, M., \& Kim, M. S. (1986). An analysis of addition and subtraction word problems in American and Soviet elementary mathematics textbooks. Cognition and Instruction, 3(3), 153-171. https://doi.org/10.1207/s1532690xci0303_1

Stump, S. L. (1999). Secondary mathematics teachers' knowledge of slope. Mathematics Education Research Journal, 11(2), 124-144. https://doi.org/10.1007/BF03217065

Stump, S. L. (2001). High school precalculus students' understanding of slope as measure. School Science and Mathematics, 101(2), 81-89. https://doi.org/10.1111/j.1949-8594.2001.tb18009.x

Teuscher, D., Reys, R. E., Evitts, T. A., \& Heinz, K. (2010). Slope, rate of change, and steepness: Do students understand these concepts? The Mathematics Teacher, 103(7), 519-524.

Usiskin, Z. (2013). Studying textbooks in an information age-a United States perspective. Zdm, 45(5), 713723. https://doi.org/10.1007/s11858-013-0514-6

Valverde, G. A., Bianchi, L. J., Wolfe, R. G., Schmidt, W. H., \& Houang, R. T. (2002). According to the Book: Using TIMSS to investigate the translation of policy into practice through the world of textbooks. Dordrecht: Springer Netherlands. https://doi.org/10.1007/978-94-007-0844-0

Walter, J. G., \& Gerson, H. (2007). Teachers' personal agency: Making sense of slope through additive structures. Educational Studies in Mathematics, 65(2), 203-233. https://doi.org/10.1007/s10649-0069048-y

Wang, Y., Barmby, P., \& Bolden, D. (2015). Understanding Linear Function: a Comparison of Selected Textbooks from England and Shanghai. International Journal of Science and Mathematics Education, 15(1), 131-153. https://doi.org/10.1007/s10763-015-9674-x

Webb, D., Boswinkel, N., \& Dekker, T. (2008). Beneath the tip of the iceberg: Using representations to support student understanding. Mathematics teaching in the middle school, 14(2), 110 - 113.

Zaslavsky, O. (2010). The explanatory power of examples in mathematics: Challenges for teaching. In M. K. Stein \& L. Kucan (Eds.), Instructional explanations in the disciplines (pp. 107-128). New York: Springer. https://doi.org/10.1007/978-1-4419-0594-9_8

Zaslavsky, O., Sela, H., \& Leron, U. (2002). Being sloppy about slope: The effect of changing the scale. Educational Studies in Mathematics, 49(1), 119-140. https://doi.org/10.1023/A:1016093305002 